DOI: $10.30612 /$ re-ufgd.v4i8.8143

\title{
PERCEPÇÃO AMBIENTAL: ESTUDO DE CASO DO PARQUE AMBIENTAL ARNULPHO FIORAVANTE, DOURADOS, MS
}

\author{
Environmental perception: case study of the Environmental Park Arnulpho Fioravante, \\ Dourados, MS \\ Emerson Machado de Carvalho ${ }^{1}$ \\ Kátia Cristina Silva Mineli² \\ Nathaskia Silva Pereira ${ }^{3}$
}

Recebido em 09/11/2017 Aceito em 15/12/2017

Resumo: A relação do homem com o meio ambiente sempre foi foco de discussão. Com o processo de urbanização essa relação tem se tornado mais frágil. O presente estudo analisou a percepção ambiental de estudantes durante uma visita técnica orientada. O local de estudo foi o Parque Ambiental Arnulpho Fioravante localizado numa região central da cidade de Dourados, MS. Os dados foram obtidos através da Associação Livre de Palavras (TALP) decorrentes da expressão indutora "a sensação que eu tenho neste local é...". Foram observados cinco pontos com diferentes características do Parque. Nos pontos que apresentavam vegetação e o mínimo de preservação os estudantes perceberam os sons da natureza, evocando uma sensação de tranquilidade. Nos pontos degradados e sem vegetação os estudantes passaram uma sensação de desconforto e perceberam principalmente os sons oriundos da poluição sonora urbana. Com estes resultados é possível constatar que mesmo diante das ações antrópicas ainda é possível encontrar conforto com o mínimo de planejamento e gestão de áreas verdes em meio ao caos urbano.

Palavras-chave: Educação Ambiental. Representações Sociais. Parques verdes urbanos. Gestão ambiental urbana.

\begin{abstract}
The present study analyzed the environmental perception of students during a guided technical visit. The study site was the Arnulpho Fioravante Environmental Park located in a central region of the city of Dourados, MS. The data were obtained through the Free Association of Words (TALP) derived from the inductive expression "the sensation that I have in this place is ...". Five points with different characteristics of the Park were observed. At the points with vegetation and the minimum of preservation, the students perceived the sounds of nature, evoking a sense of tranquility. At the degraded and unvented points, the students experienced a sense of discomfort and noticed mainly the sounds from urban noise pollution. With these results it is possible to verify that even with the anthropic actions it is still possible to find comfort with the minimum of planning and management of green areas in the midst of urban chaos.
\end{abstract}

Keywords: Environmental Education. Social Representations. Urban green parks. Urban environmental management.

\footnotetext{
'Professor Adjunto da Universidade Federal da Grande Dourados - UFGD, Faculdade de Ciências Biológicas e Ambientais - FCBA - E-mail: emersoncarvalho@ufgd.edu.br;

${ }^{2}$ Bacharel em Ciências Biológicas pela Universidade Federal da Grande Dourados - UFGD, Faculdade de Ciências Biológicas e Ambientais - FCBA;

${ }^{3}$ Mestre em Biologia Geral/ Bioprospecção pela Universidade Federal da Grande Dourados - UFGD
} 


\section{Introdução}

O intensivo processo de industrialização e urbanização ocasionou reflexos notáveis na qualidade de vida dos indivíduos na cidade, que até então não estava preparada para absorver tamanho crescimento populacional (CANEPA, 2007). De acordo com relatório da Organização das Nações Unidas - ONU, estima-se que a população humana alcançará 8,5 bilhões em 2030, 9,7 bilhões em 2050 e passará os 11 bilhões em 2100 (PNUD, 2015). Este salto da população humana poderá comprometer ainda mais a qualidade ambiental e, consequentemente a qualidade de vida da população dos centros urbanos.

O homem tem apresentado dificuldade de se reconhecer ou se perceber como parte integrante do meio em que vive (meio ambiente), apresentando uma concepção de que a "natureza" está a seu serviço e, muitas vezes, como produto do capitalismo (NEUENFELDT; MAZZARINO， 2016; PITANGA et al., 2017). O contato esporádico do ser humano com a natureza não é o suficiente para justificar uma mudança de comportamento perante as questões ambientais, uma vez que este indivíduo está cotidianamente envolvido por um contexto imerso nos valores de uma sociedade que segue a lógica do capital, da produção e do consumo (FLORIANI, 2010; RODRIGUES, 2010). Neste contexto, como mitigar os impactos ambientais do atual estágio de desenvolvimento de produção capitalista?

A Educação ambiental tem se projetado como uma ferramenta pautada em estratégia metodológica da Gestão Ambiental, tendo em vista a crise da racionalidade (ASSIS; RUTKOWSKI, 2017). Ela tem sido vista por muitos como uma das alternativas para reconhecer e mitigar os problemas ambientais gerados no mundo contemporâneo (SANTOS et al., 2017). Nunes e Bomfim (2017) indicam também a importância em desenvolver a sensibilidade dos indivíduos, propondo uma estética crítica, voltada para a contemplação da realidade, contrapondo-se aos valores construídos pela sociedade de mercado. No entanto, ainda presenciamos a Educação Ambiental hermeticamente curricular e contextualizada em sala de aula, apropriada segundo o que é próprio de cada ciência, que é defendida isoladamente por uma disciplina, assumindo assim uma visão reducionista e unilateral do discurso ambientalista (AMORIM et al., 2017). Como romper com esta construção unilateral, reducionista e até certo ponto romântica que a Educação Ambiental tem se 
alicerçado e estreitar ainda mais os laços afetivos entre o ser humano e a natureza?

A retorica de se repensar o indivíduo pertencente ao meio e vinculado a ele, torna se um desafio necessário, e enfatizar os benefícios do meio ambiente e os prejuízos de nossas atitudes, precisa promover ao censo comum um olhar diferenciado e reflexivo que estimule levar em consideração significados, valores, cultura e meio social (LIMA; SILVA, 2011). Factualmente, as propostas de Educação Ambiental mais difundidas estão pautadas em estudos no meio se baseiam em metodologias que propõem visitas orientadas a ambientes conservados objetivando uma vivência prática com ênfase nos valores ambientais trabalhados em sala de aula (RODRIGUES, 2010). O objetivo principal é criar uma afinidade de indivíduos com o meio natural, pelo contato direcionado à natureza através de atividades de sensibilização integradas ao meio, buscando uma consequente educação à preservação.

É importante compreender que a Educação Ambiental surgiu por volta de 1960 num contexto de mudanças sociais,

A constante negligencia de áreas verdes no espaço urbano é um agravante para a qualidade de vida da população. Além do empobrecimento da paisagem urbana, são que a princípio favorecia apenas o aprendizado de conceitos ecológicos (SANTOS et al., 2017). Desde estão, nestes quase 60 anos de Educação Ambiental presenciamos muitas transformações culturais, sociais e ambientais. A busca contínua por uma Educação Ambiental mais crítica, transformadora e voltada para os problemas socioambientais têm sido uma das grandes promessas para promoção do desenvolvimento sustentável. Mas a quantos passos estamos desta conquista?

\section{A Educação Ambiental está} apresentada neste relato de experiência e pesquisa descritiva-exploratória, como um processo que busca perceber o sujeito no seu espaço e, dessa forma, sensibilizar e aumentar a percepção destes em relação à responsabilidade ambiental na construção de melhor qualidade de vida. Para tal, foi adotado como espaço do estudo um parque verde no centro de Dourados, MS. O parque representa hoje para os munícipes uma área de lazer, recreação e contemplação da natureza, ao mesmo tempo em que se contrasta com a falta de manutenção e preservação dos recursos e infraestrutura ali disponíveis.

inúmeros e de diferentes amplitudes os problemas que podem ocorrer, em virtude da interdependência dos múltiplos subsistemas que coexistem numa cidade (LOBODA; 
ANGELIS, 2005). A disposição de vegetação pode aumentar a capacidade de redução da temperatura do ar e a atenuação da radiação incidente, intensificando assim as sensações de conforto térmico, ou seja, índices em que o ser humano sinta confortabilidade em decorrência de condições térmicas agradáveis ao corpo (LABAKI et al., 2011). Além do desconforto térmico, outro produto decorrente das alterações antrópicas e do crescimento populacional nos centros urbanos são os níveis de ruídos produzidos, também conhecidos como poluição sonora.

Conforme mencionado, as áreas verdes urbanas são importantes na manutenção da qualidade de vida através da atenuação da poluição sonora e desconforto térmico, promoção de recreação e lazer, bem como coadjuvantes na sensibilização da preservação do meio ambiente.

O presente estudo pretende trazer algumas dessas discussões através da percepção dos estudantes em visita técnica orientada em um parque verde urbano.

\section{Local de Estudo}

O presente estudo foi desenvolvido no Parque Ambiental Arnulpho Fioravante, localizado no perímetro urbano da cidade de Dourados, MS (Figura 1). O município de Dourados está localizado no sul do Estado de Mato Grosso do Sul, região Centro-Oeste e possui uma população de aproximadamente 218.069 mil habitantes em uma área Territorial de $4.086 .237 \mathrm{~km}^{2}$ de Altitude Média: 430 metros (IBGE, 2017).

O clima da região é considerado de transição entre o tropical e o subtropical e segundo a classificação de Köppen é do tipo Aw úmido com inverno seco, verão chuvoso, onde a temperatura média do mês mais frio é inferior a $18^{\circ} \mathrm{C}$ e a do mês mais quente superior a $22^{\circ} \mathrm{C}$. A temperatura média anual varia de 20 a $22^{\circ} \mathrm{C}$, com as médias dos meses mais frio e mais quente oscilando, respectivamente, de 15 a $19^{\circ} \mathrm{C}$ e de 23 a $26^{\circ} \mathrm{C}$ (OLIVEIRA et al., 2011). 


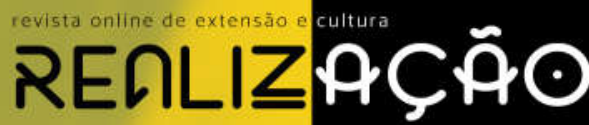

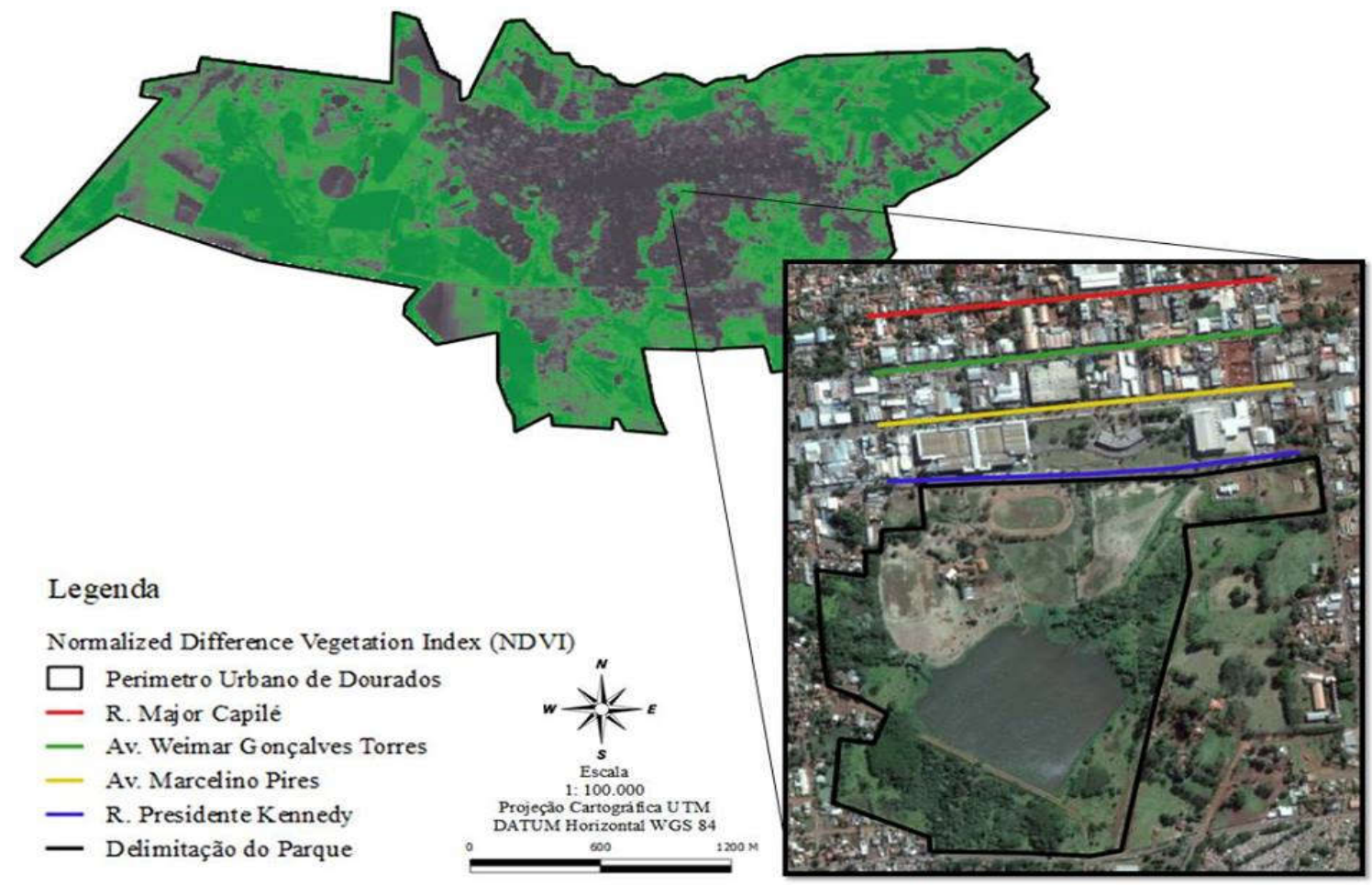

Figura 1. Localização do Parque Arnulpho Fioravante na cidade de Dourados, MS e principais avenidas contíguas. Fonte: Rick Mauricio R. dos Santos.

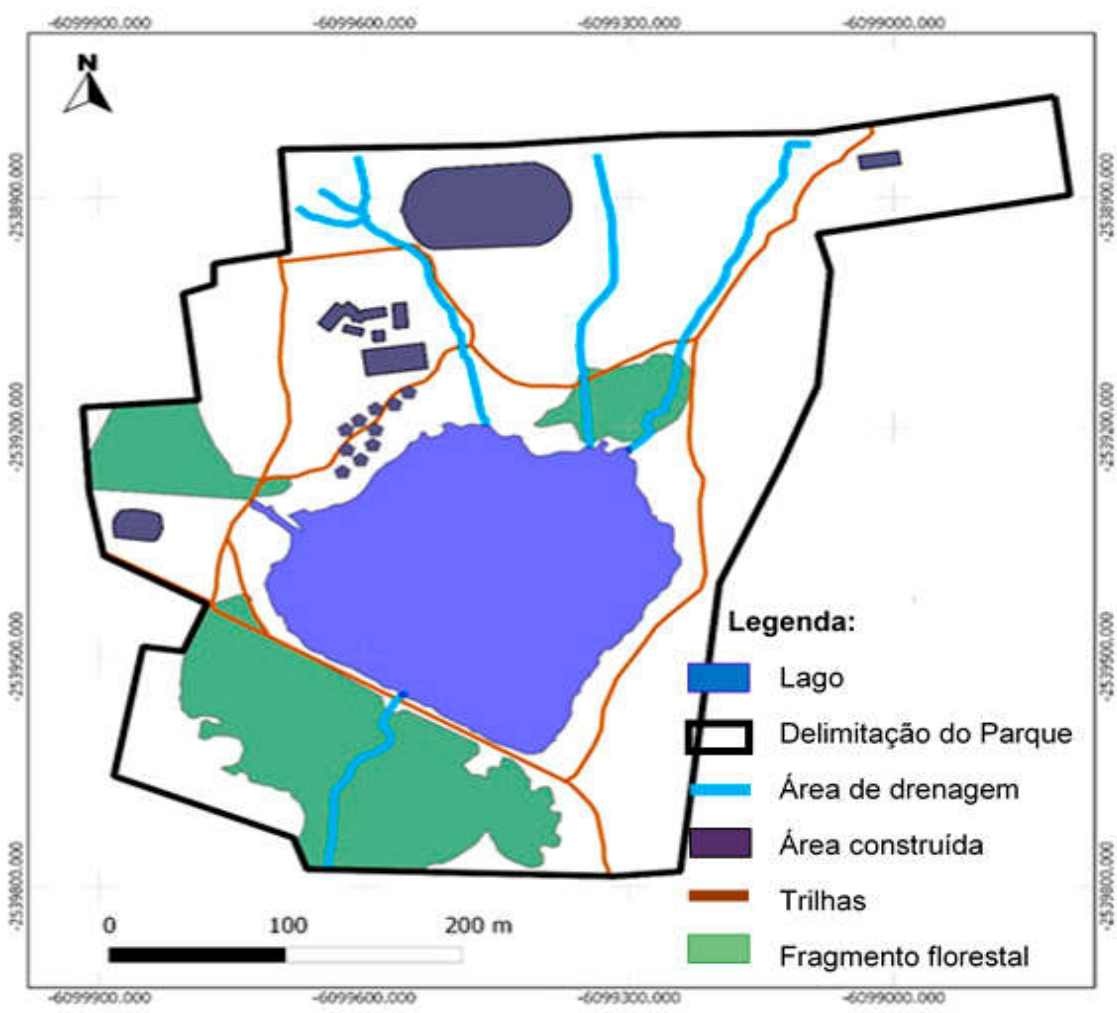

Figura 2.

Demarcação do Parque Ambiental Arnulpho Fioravante e seus principais recursos. Fonte: Google Imagem. Edição: Giovana Pinheiro (2016). 


\section{O Parque Ambiental Arnulpho}

Fioravante tem ganhado visibilidade na cidade de Dourados, pois encontra-se nas imediações do shopping local, de pontos comerciais, hotéis e estação rodoviária. O parque possui uma área de 73 hectares, localizado entre as coordenadas S $22^{\circ} 14^{\prime}$ 03,10" e W 54 47' 47,52" e S $22^{\circ} 13^{\prime} 34,52^{\prime \prime}$ e W $54^{\circ} 47^{\prime} 11,12^{\prime}$. Nas áreas periféricas do Parque encontram-se os prédios do IMAM Instituto de Meio Ambiente de Dourados e da Guarda Municipal - GM e Quartel da Policia Militar Ambiental - PMA. No Parque também são encontradas áreas de recreação e laser, como quadras de esporte, pista de atletismo, quiosques com bancos, mesas e churrasqueira, trilhas para caminhada, riachos e uma lagoa com comprimento médio de 350 metros (Figura 2). No entanto, a infraestrutura do Parque encontra-se em estado de degradação, tanto nos recursos ambientais quanto nas áreas construídas, remetendo a um local abandonado ou negligenciado pelo poder público.

\section{Metodologia}

O presente estudo trata-se de uma pesquisa qualitativa, do tipo exploratóriodescritivo, sendo realizada em duas etapas: (1) visita técnica orientada de percepção ambiental no Parque Ambiental Arnulpho Fioravante; (2) análise da percepção dos estudantes sobre o Parque através da associação livre de palavras.

O público amostral foi composto por estudantes dos cursos de Gestão Ambiental e Ciências Biológicas (25 indivíduos) regularmente matriculados na disciplina de Educação Ambiental da Faculdade de Ciências Biológicas e Ambientais - FCBA da Universidade Federal da Grande Dourados - UFGD.

\section{Visita técnica}

Durante a visita técnica ao Parque utilizou-se como trajeto uma trilha do parque que dava acesso aos principais atrativos e contornava a lagoa. Em cada ponto selecionado para percepção os estudantes foram orientados a ficar em silêncio, fechar os olhos e perceber o ambiente ao redor. Para tal foram selecionados cinco pontos dentro do parque com diferentes características. $\mathrm{Na}$ sequência os estudantes deveriam registrar através de três palavras a sensação percebida.

\section{Análise dos dados}

Os métodos utilizados para avaliar a percepção dos estudantes foram adaptados do estudo de Cardoso e Carvalho (2017), apresentados no livro "Planejamento e gestão do turismo sob a perspectiva do público e do privado”. Os métodos estão apresentados na sequência: 
O TALP foi utilizado com intuito de investigar a percepção sensorial que os estudantes apresentaram em relação aos pontos do Parque, através da expressão indutora: “A sensação que tenho neste local é...”. O TALP foi uma ferramenta originalmente utilizada na prática clínica, utilizado no campo da psicologia social em pesquisas sobre representações sociais. Através do TALP os alunos escreveram três palavras que tinham relação como a expressão indutora supracitada. As palavras escolhidas pelos estudantes foram anotadas em bloco de papel. Ao final do percurso da trilha foi solicitado aos estudantes que justificassem brevemente uma das palavras escolhidas, de forma a tentar captar a percepção racional na experiência vivenciada.

A partir das palavras escolhidas no TALP pelos estudantes foram geradas cinco nuvens de palavras criadas no programa WordItOut para a representação visual da percepção sensorial. A nuvem das palavras foi construída utilizando a contagem simples das ocorrências das palavras apresentadas em cada um dos pontos de percepção do Parque. Nessa representação cada palavra tem seu tamanho destacado pela relevância atribuída pela contagem simples das ocorrências de determinada palavra no teste. Por exemplo, uma palavra citada 30 vezes terá proporcionalmente o dobro de tamanho de uma palavra citada 15 vezes.

\section{Resultados e Discussão}

A Associação Livre de Palavras (TALP), a partir da expressão indutora "a sensação que eu tenho neste local é..." obteve um dicionário de 124 palavras. Contudo, as palavras sinônimas e semanticamente semelhantes foram agrupadas e reduzidas para tratamento dos dados. As palavras produzidas pelos estudantes em seus respectivos pontos de observação podem ser verificadas das Figuras 3 a 7.

No ponto 1 de observação foi representado por palavras que evocam sentido de caos e estresse provocados, principalmente, por poluição sonora dos grandes centros. Agitação, carros e barulho estiveram em destaque, seguidos em menor representatividade por pássaros, estresse e vento (Figura 3a). Este ponto de observação teve com principais características pouca cobertura vegetal, muita incidência luminosa, campo aberto e área limítrofe do perímetro urbano (Figura 3b). Dessa forma, é possível observar que, mesmo em um parque verde é preciso ter condições mínimas de conforto térmico e de barragem dos ruídos para que ele possa proporcionar uma fuga do estresse e caos dos grandes centros. Em todo o momento foi observado 
que os agravantes do estresse estiveram presentes, mascarando o som dos pássaros e do vento nas folhas.

Já é de conhecimento a importância de áreas com vegetação no perímetro urbano para atenuação do calor e manutenção da umidade do ar. Porém, autores como Nucci e Cavalheiro (1999), Andrade (2005) e Maia (2010) também consideram a vegetação urbana umas das mais eficientes barreiras na redução da poluição sonora. A vegetação proporciona amortecimento dos ruídos de fundo sonoro contínuo e descontínuo de caráter estridente, que são ocorrentes nas grandes cidades (LOBODA; ANGELIS, 2005).

No ponto 2 de observação foi representado principalmente pelas palavras água e pássaros, seguido em menor representatividade por calma, frescor e trator (Figura 4a). Nota-se neste ponto que apenas a última palavra apresentou uma conotação negativa, enquanto que as demais remetiam à tranquilidade e natureza. É válido lembrar que este ponto estava localizado a apenas 150 metros do primeiro ponto. No entanto, as características ambientais que diferem do primeiro ponto foi sombreamento por árvores de grande porte e a presença de um pequeno riacho com trechos encachoeirados (Figura 4b). A presença do trator na percepção dos estudantes se deu em decorrência de um serviço de roçada que estava ocorrendo naquele momento. Isso nos faz perceber que até mesmo as atividades rotineiras de manutenção em parques verdes precisam ser planejadas de forma a não tirar a tranquilidade dos visitantes e causar impactos na fauna e flora local.

\section{O ponto 3 foi representado,} principalmente, pela palavra calor, seguido por desconforto, abafado e barulho (Figura 5a). Tais palavras são indicadoras de desconforto térmico e sonoro, ou seja, o oposto que se esperaria de um parque verde urbano. Este ponto fica em uma área recém roçada por trator e aparentemente não apresenta qualquer propósito para estar sem vegetação (Figura 5b).

Entrevistas de opinião com a população demonstraram que a existência de parques urbanos e a sua utilização trazem inúmeros benefícios para a saúde do ser humano, entre esses benefícios está a atenuação de ruídos urbanos (MARTINS; ARAÚJO, 2014). A disposição adequada de vegetação pode aumentar a capacidade de redução da temperatura do ar e atenuação da radiação incidente, intensificando assim as sensações de conforto térmico (LABAKI et al., 2011).

No entanto, é necessário um plano de manejo, mesmo que sucinto, e que apresente um zoneamento das áreas utilitárias do 
parque. Dessa forma será possível evitar que áreas destinadas à preservação e conservação dos recursos naturais sejam O ponto 4 de observação foi representado, principalmente, pelas palavras vento, tranquilidade, frescor, confortável e pássaros (Figura 6a). Este local está apenas 30 metros do ponto 3, mas apresenta elevada densidade de árvores com sombreamento (Figura 6b). Ficou perceptível o quanto a vegetação, principalmente árvores de grande porte, são importantes para desconectar o homem do cotidiano urbano e aproximá-lo da natureza.

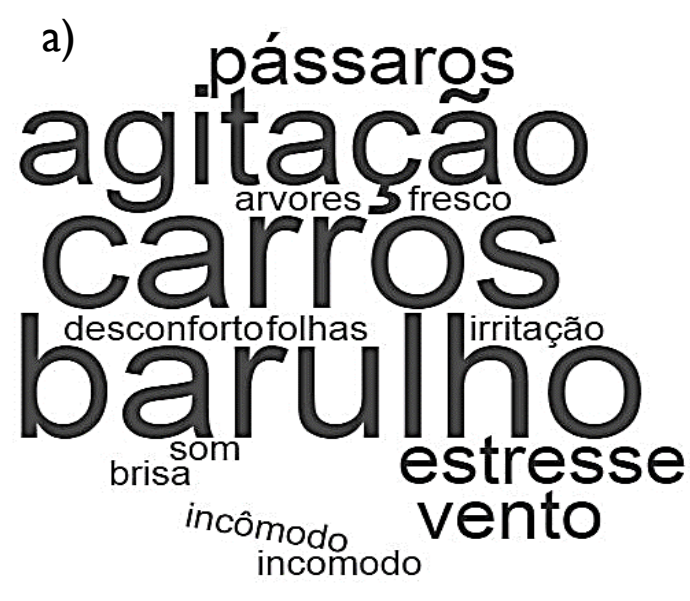

degradadas despropositadamente pelo órgão responsável pela manutenção do mesmo.

Semelhante ao ponto anterior, o ponto 5 foi representado por palavras positivas. Destaca-se a palavra confortável, seguida por tranquilidade, frescor, sossego, paz e vento (Figura 7a). Este ponto apresenta uma elevada diversidade e densidade de espécies arbóreas nativas, e é o ponto de escoamento da lagoa, afluente do córrego Paragem. Além disso, a paisagem é moldada por grandes rochas que formam trechos encachoeirados ao longo do afluente.

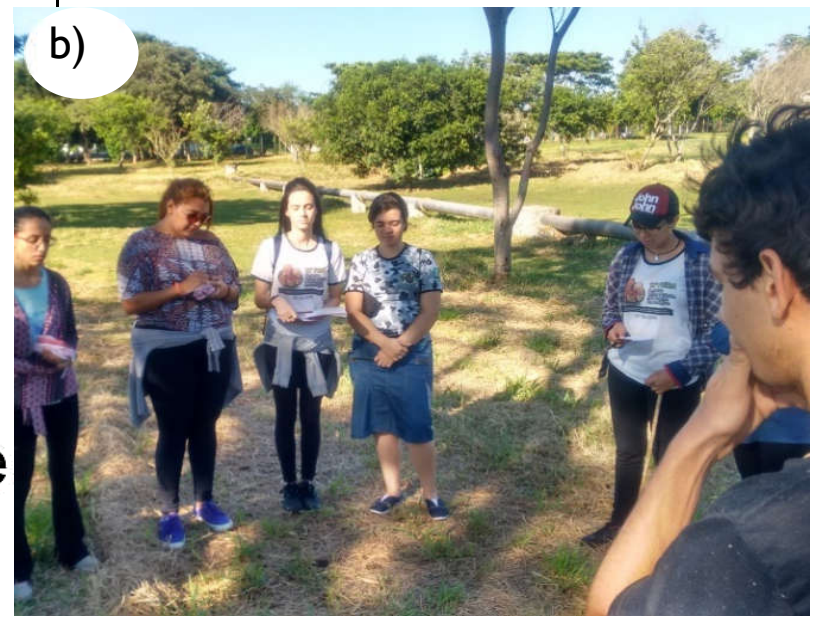

Figura 03. a) nuvem de palavras geradas através da expressão indutora "a sensação que eu tenho neste local é...” b) e ponto 1 de observação no Parque Ambiental Arnulpho Fioravante. 


\section{REดLIZIAÇĂ $\odot$}

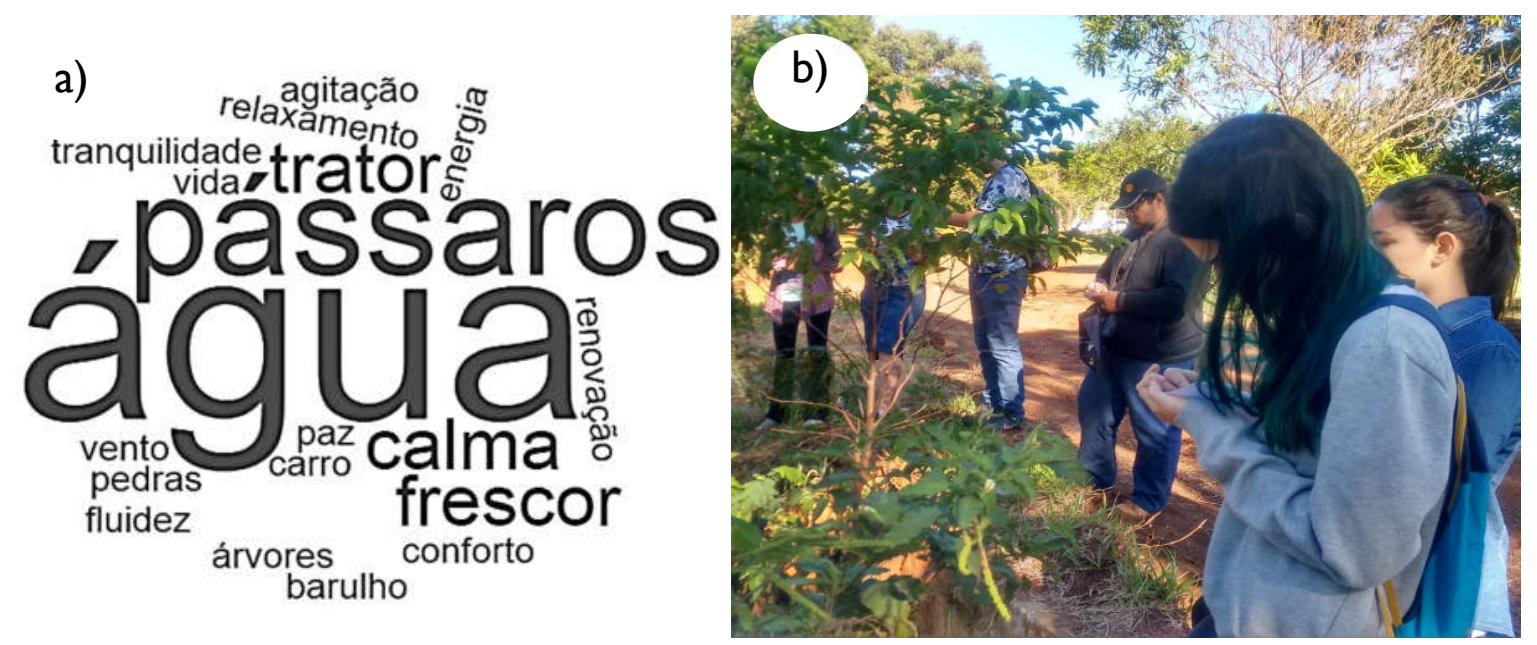

Figura 04. a) nuvem de palavras geradas através da expressão indutora "a sensação que eu tenho neste local é..." b) e ponto 2 de observação no Parque Ambiental Arnulpho Fioravante.
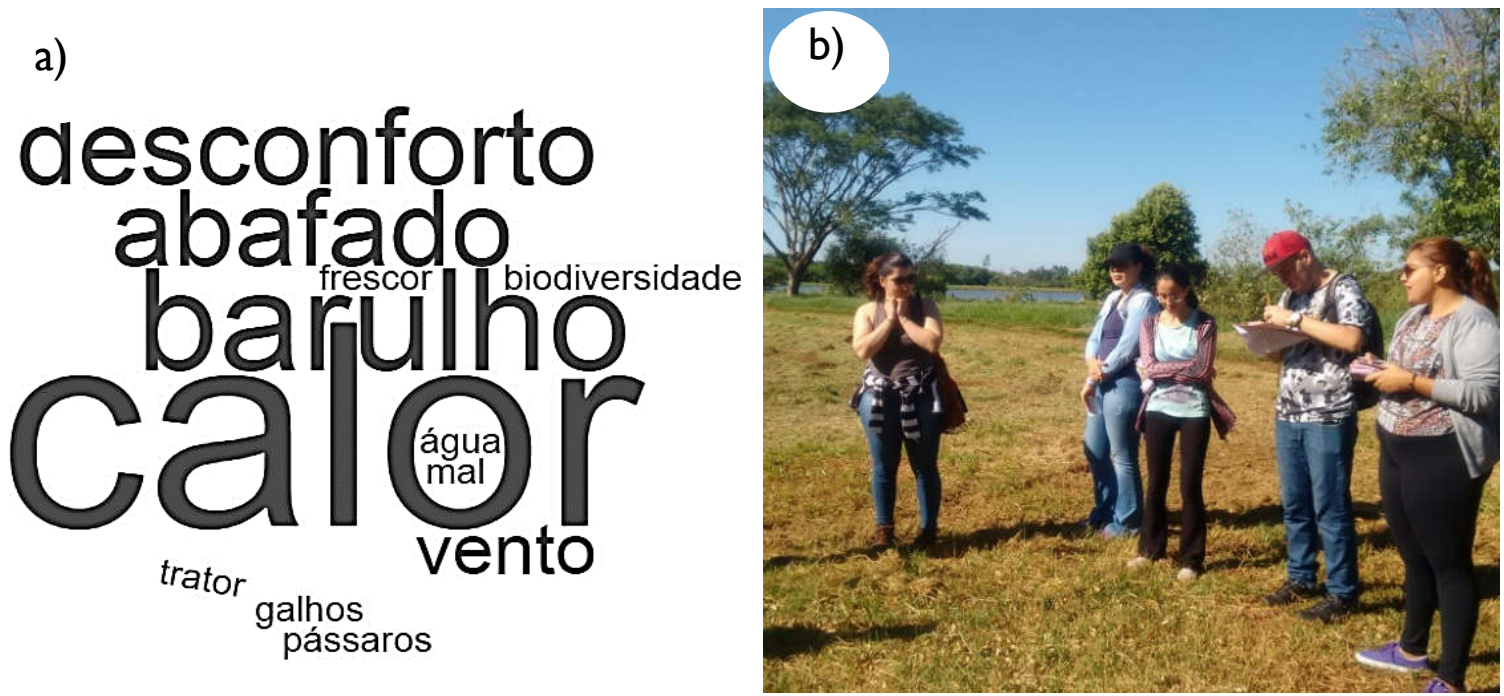

Figura 05. a) nuvem de palavras geradas através da expressão indutora "a sensação que eu tenho neste local é..." b) e ponto 3 de observação no Parque Ambiental Arnulpho Fioravante. 


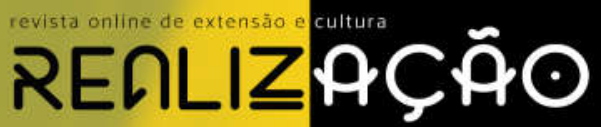

a)

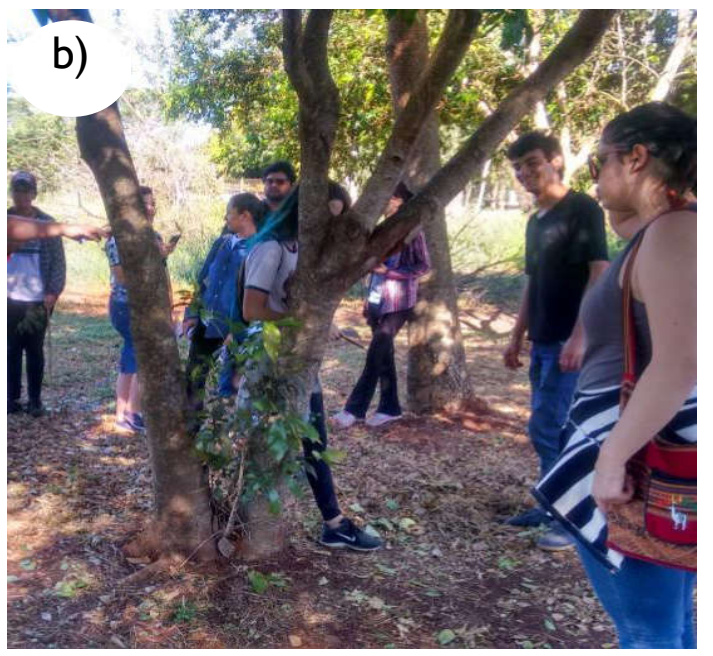

Figura 06. a) nuvem de palavras geradas através da expressão indutora "a sensação que eu tenho neste local é...” b) e ponto 5 de observação no Parque Ambiental Arnulpho Fioravante.
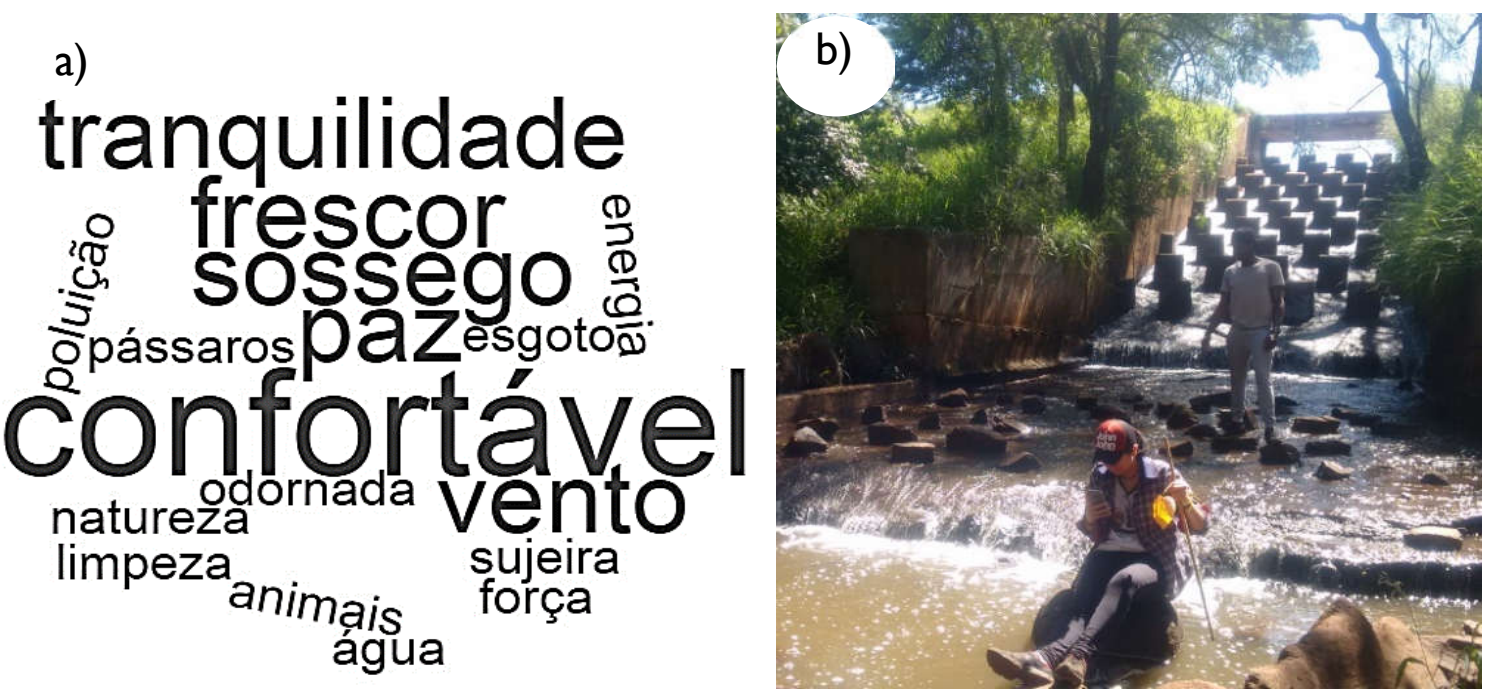

Figura 07. a) nuvem de palavras geradas através da expressão indutora "a sensação que eu tenho neste local é..." b) e ponto 4 de observação no Parque Ambiental Arnulpho Fioravante.

\section{Considerações finais}

De acordo com a percepção ambiental dos estudantes, os pontos 2,4 e 5 apresentaram os melhores atributos para um parque verde urbano. Os resultados indicaram que nestes locais é possível relaxar e entrar em sintonia com a natureza. No entanto, eles não estão livres dos problemas relacionados a preservação e conservação dos recursos naturais e manutenção do Parque. Tais apontamentos 
estiveram imbricados nas palavras de baixa representatividade. Dessa forma, é possível constatar que mesmo diante das ações antrópicas ainda é possível encontrar conforto com o mínimo de planejamento e gestão de áreas verdes em meio ao caos urbano.

\section{O Parque Ambiental Arnulpho} Fioravante apresenta muitos aspectos positivos, que contribuem com a melhora da qualidade de vida das pessoas que $o$ frequentam. Entretanto, tais aspectos se contrastam com os atributos negativos, que se melhorados poderão potencializar todos os benefícios que este parque pode trazer para a comunidade. Para tal é importante se pensar num plano de manejo para o Parque e que, necessariamente, leve em consideração planos de ação de recuperação das áreas degradadas. Essas áreas verdes interferem diretamente na qualidade de vida dos seres humanos quando se considera as funções estéticas, educativas, sociais e ecológicas, que atuam na amenização das consequências negativas da urbanização.

\section{Referências}

AMORIM, C. D.; CESTARI, L. A. S.; SILVA JÚNIOR, M. F. Educação Ambiental e Interdisciplinaridade: um olhar sobre as ações extensionistas da área de conhecimento "Meio Ambiente e Sustentabilidade" de uma IES do Sudoeste da Bahia. Revista Eletrônica do Mestrado em Educação Ambiental, v. 34, n. 3, p. 186-206, 2017.

ANDRADE, H. O clima urbano - Natureza, escalas de análise e aplicabilidade. Finisterra, Lisboa, Portugal, v. 40, n. 80, p.67-91, 2005.

ASSIS, A. E. S. Q.; RUTKOWSKI, E. W. Educação Ambiental como estratégia metodológica da Gestão Ambiental: Por uma nova postura epistêmica. Revista Eletrônica do Mestrado em Educação Ambiental. v.33, n.3, p. 110-124, 2016.

BRASIL. IBGE. Censo Demográfico, 2017. Disponível em:https://www.ibge.gov.br/ > Acesso em: Fevereiro de 2018.

CANEPA, C. Cidades sustentáveis: o município como locus da sustentabilidade. São Paulo: SCS, 2007.

CARDOSO, C. A.; CARVALHO E. M. Educação para o Turismo: Representações sociais de Estudantes do Ensino Básido de Bonito-MS. In: Planejamento e gestão do turismo sob a perspectiva do público e do privado. São Carlos: Pedro e João Editores 341 p., 2017.

FLORIANI, D. Diversidade Cultural, Desafios Educacionais E Sistemas Cognitivos: Para Pensar Uma Modernidade Em Crise. Revista Eletrônica do Mestrado em Educação Ambiental. v. especial, 2010. 
LABAKI, L. C.; SANTOS, R. F. dos; BARTHOLOMEI, C. L. B; ABREU, L. V. Vegetação e conforto térmico em espaços urbanos abertos. Revista Fórum Patrimônio, Belo Horizonte - MG, v. 4, n. 1, p. $23-42,2011$.

LEFÈVRE, F.; LEFÈVRE, A. M. C. O discurso do sujeito coletivo: um novo enfoque em pesquisa qualitativa (desdobramentos). Caxias do Sul: Editora Educs, 256 p., 2005.

LIMA, R. L.; SILVA, V. P. Gestão ambiental para o turismo excursionista do olheiro de PurezaRN: uma contribuição da percepção de moradores e excursionistas. Holos, Natal, v.3, ano 27, p. 120-137, 2011.

LOBODA, C. R.; DE ANGELIS, B. L. D. Áreas verdes públicas urbanas: conceitos, usos e funções. Ambiência, Guarapuava, v.1, n.1, p.125-139, 2005.

MAIA, D. S. N. Ruído De Parques Eólicos Análise e Caracterização. 2010. 130 f. Dissertação (Mestrado em Engenharia Civil - Especialização em Construções) Universidade do Porto. Faculdade de Engenharia. 2010.

MARTINS, R. T. P.; ARAUJO, R. S. Benefícios dos parques urbanos. Perspectivas online. Brasil, v. 10, n. 4, p. 38-44, 2014.

NEUENFELDT, D. J.; MAZZARINO, J. M. O corpo como lugar onde a experiência da educação ambiental nos toca. Revista Eletrônica do Mestrado em Educação Ambiental, v. 33, n. 1, p. 22-36, 2016.

NUCCI, J. C; CAVALHEIRO, F. Cobertura vegetal em áreas urbanas - conceito e método Revista GEOUSP: Espaço e Tempo (online), n. 6, p. 29-36, 1999.

NUNES, L. S. R.; BOMFIM, A. M. Estética e Educação Ambiental: primeiras reflexões sobre cenários e imagens no processo de alienação da natureza. Revista Eletrônica do Mestrado em Educação Ambiental, v. 34, n. 3, p. 245-262, 2017.

OLIVEIRA, C. F. Ecoturismo como prática para o desenvolvimento socioambiental. Revista Brasileira de Ecoturismo, São Paulo, v. 4, n. 2, p. 184-195, 2011.

PITANGA, A. F.; NEPOMUCENO, A. L. O.; ARAUJO, M. I. Os Entendimentos e Práticas de Ensino de Professores Universitários em Educação Ambiental. Revista Eletrônica do Mestrado em Educação Ambiental, v. 34, n.1, p. 270-289, 2017.

PNUD, Programa das Nações Unidas para o Desenvolvimento. Transformando Nosso Mundo: A Agenda 2030 para o Desenvolvimento Sustentável. Rio de Janeiro, 2015.

RODRIGUES, C. Observando Os "Estudos Do Meio" Pela Lente da Educação Ambiental Crítica. Revista Eletrônica do Mestrado em Educação Ambiental, v. 24, 2010.

SANTOS, D. B.; SOUZA, C. R.; MOREIRA, L. M. Da educação ambiental à transformação social: reflexões sobre a interdisciplinaridade como estratégia desse processo. Revista Eletrônica do Mestrado em Educação Ambiental, v. 34, n. 2, p. 156-172, 2017. 